\title{
National Perinatal Association Health Equity Group
}

Sigride Jean-Sicard BSN, MSN, PNP-PC,CLC

The National Perinatal Association (NPA)is an interdisciplinary organization that strives to be a leading voice for perinatal care in the United States. Our diverse membership is comprised of healthcare providers, parents \& caregivers, educators, and service providers, all driven by their desire to give voice to and support babies and families at risk across the country.

Members of the NPA write a regular peer-reviewed column in Neonatology Today.

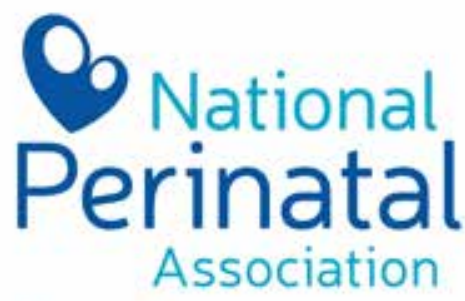

Educate. Advocate. Integrate.

"This interview is part of an ongoing series highlighting the lives and perspectives of people working to improve health equities in perinatal spaces."

This interview is part of an ongoing series highlighting the lives and perspectives of people working to improve health equities in perinatal spaces. This month, we asked about the journey and career of

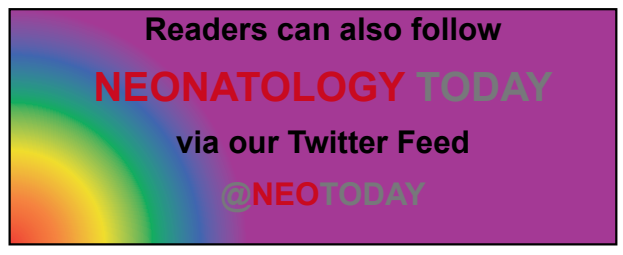

Sigride Jean-Sicard, a NICU nurse and nurse practitioner, who is also in the first generation of her family to be born in the United States after her parents migrated from Haiti.

Even from a young age, Sigride has known she wanted to work in medicine.

"My mom is an early education teacher for 3- and 4-year-olds, and I think I get my love [of] children, especially babies, from her," she said. "Once I decided that I wanted to go into nursing, I always knew I wanted to work with children."

That work, as a nurse in the pediatric critical care float pool, brings her to pediatrics, the PICU, and the NICU. There, some of her life experiences as a first-generation migrant have affected how she relates to patients and their families.

"I think that my perceptions are slightly different because I am first generation," she said. Both of her parents were born in Haiti and met while living in the U.S., and they speak both English and Haitian Creole at home.

"As a young child, I also had classic books in French. Two specifically I can remember are Beauty and the Beast and A Little Mermaid. I also grew up listening to my dad's music tapes in French.

"So when I have patients of color who have only been in the country for a couple of years or even patients of color that have lived in the U.S. their entire lives, I feel as though I have something in common with them. When interacting with patients whose children are going to be first-generation, I think of it as 'You have done an amazing thing for your child. They can be and do anything they wish to do. I feel like I am a perfect example of that."

Her experiences as a first-generation migrant also support a belief that "even for people of color who have lived here their entire lives, race doesn't have to have to be a barrier that holds you back. You can still succeed."

Some of this carries echoes of the support she received from her parents, whom Sigride regards as role models for herself and her two older sisters, "because they are so hardworking and determined." She attributes her success to them because "they've always encouraged us no matter what our endeavors have been."

\section{"That work, as a nurse in} the pediatric critical care float pool, brings her to pediatrics, the PICU, and the NICU. There, some of her life experiences as a first-generation migrant have affected how she relates to patients and their families."

Also, while she is not sure if she has noticed any barriers she has faced specifically due to her being a woman of color, she said, "... it was definitely evident that there were only four people of color in my entire nursing class, which consisted of roughly two hundred ... people."

Before nursing school, however, Sigride thought she wanted to pursue pre-medical studies and enrolled at Providence College in Providence, Rhode Island, for one year. She then transferred to Quinnipiac University in Hamden, Connecticut, where she met with faculty from their nursing program and had experiences that changed her trajectory.

"When I got to listen to the beating heart of a newborn simulation doll, I knew this was what I had to do," she said. "It was the most amazing thing."

This motivated Sigride to transfer into the nursing prerequisite classes and apply to the nursing program. By the end of the semester, she had been accepted into the program. Even with the change in majors during her first year, Sigride graduated in four years, as she had planned, even though it required that she take multiple classes during the summer. 
During the early stages of her nursing education, Sigride worked as a labor and delivery scrub tech and had a pivotal experience when helping with a cesarean section "on a baby that came out very sick.

"I was able to follow the case and see what then occurred in the special care nursery," she said. "I got to see the attending doctor perform a procedure on the baby so that the baby could be given blood. It was at the moment I again had a wow moment." It was clear to her then: "I want to be able to do that!!"

So, during her senior year of nursing school, Sigride applied to nurse practitioner school. "I am and was very determined. This was my dream, and I was not going to let anything get in my way," she said.

\section{"But the patient families with whom she interacts don't always know her academic history, so we asked about the ways she may have been able to offer support because of her cultural connections and experiences."}

After graduating with her nursing degree, Sigride obtained her Master's Degree in Nursing from Northeastern University.

But the patient families with whom she interacts don't always know her academic history, so we asked about the ways she may have been able to offer support because of her cultural connections and experiences.

"I have definitely and many a time walked into a patient's room and seen their faces light up when they see that I am a person of color as well and that I look like them," she said.

"Also, sometimes I have heard in the nursing report that a parent or parents have been difficult. However, I would then meet them and then have no issues with the parent. It has often made me wonder whether or not it had something to do with me looking like them, a person of color.

"One instance I can think of that happened was a mother ... of color that had multiple complications. Rightfully so, she was very anxious during her pregnancy. Towards the end of the pregnancy, she presented to antenatal every day because she was worried there was something wrong with her baby. The day she ended up being admitted, the nurse was very rude to her and said very unprofessional things such as, 'my shift already ended. I shouldn't be here right now."”

"It was when she told me this that I wondered to myself, "Would this have happened if she were white? Would the nurses have been more understanding of this mom's perfectly appropriate anxiety that caused her to come to antenatal multiple days in a row?'

"Although the hospital I work at [has] a large amount of people of color [on staff], I still couldn't help but wonder if this would have happened if the mom was white. It has become more evident in recent years of the innate discrimination that lies within the U.S., especially in the health care system and the subconscious dis- crimination that many people have."

That curiosity is an ongoing theme in Sigride's reflections. "I embrace learning about different cultures and their values and beliefs," she said. "It is and always has been something I find interesting."

In addition to having opportunities to do that, she also has her dream job, where she said she gets to work with parents and babies of color almost every day who look exactly like her.

The Health Equities Workgroup of the National Perinatal Association would like to thank Sigride Jean-Sicard for generously sharing her time and stories with us and allowing us to share them with you.

For more information about the NPA Health Equities Workgroup or to give feedback or suggest someone you think we should interview, please contact Tiffany A Moore, PhD, RN, SANE-A at tamoore@unmc.edu

Disclosure: The National Perinatal Association www.nationalperinatal.org is a 501c3 organization that provides education and advocacy around issues affecting the health of mothers, babies, and families.

NT
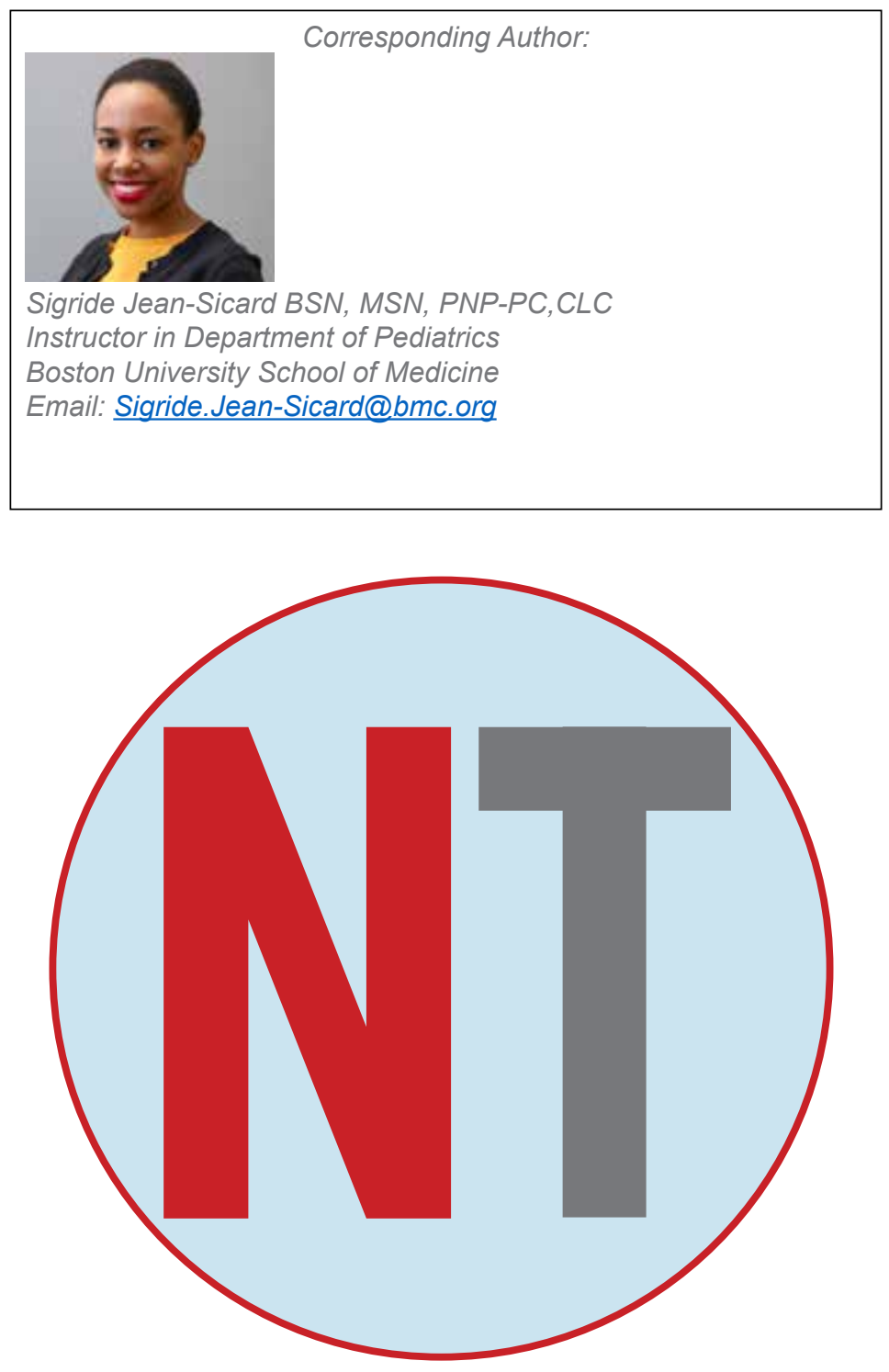